\title{
Metabolic changes in obese patients after laparoscopic gastric bypass: five-year experience in a tertiary referral hospital
}

\author{
Efectos metabólicos en pacientes obesos posoperados de bypass gástrico \\ laparoscópico: 5 años de experiencia en un hospital de tercer nivel
}

\author{
José D. Hernández-Marín*, César A. Marrufo-Patrón and Federico López-Rosales
}

Hospital Regional de Alta Especialidad de la Península de Yucatán, Mérida, Yucatán, Mexico

\begin{abstract}
Background: Obesity is defined as a disease characterized by an abnormal or excessive accumulation of adipose tissue that may be hazardous to the health. Bariatric surgery is an effective and safe treatment of morbid obesity. Materials and Methods: $A$ review and analysis of 90 clinical records of postoperative patients with laparoscopic gastric bypass was performed. Results: 38 patients were included in the study; 17 (43.6\%) of which were diagnosed with diabetes mellitus before the procedure and 21 patients (56.4\%) without diabetes mellitus. In non-diabetic patients, it was found statistical differences in the value of bodymass index (BMI). In the group of diabetic patients, statistical differences were found in the value of BMI, glycated hemoglobin and uric acid. Conclusions: Laparoscopic gastric bypass (LRYGB) provides a satisfactory weight loss and BMI reduction, specifically, percent of excess BMI lost with the simultaneous improvement of comorbid disease.
\end{abstract}

KEY WORDS: Obesity. Diabetes. Gastric bypass. Metabolic effects.

\section{Resumen}

Introducción: La obesidad se define como una enfermedad caracterizada por una acumulación anormal o excesiva de grasa que puede ser perjudicial para la salud. La cirugía bariátrica es un método efectivo y seguro en el tratamiento de la obesidad extrema. Materiales y Métodos: Se realizó una revisión y análisis de 90 expedientes clínicos de pacientes post-operados de bypass gástrico laparoscópico. Resultados: De los 38 pacientes incluidos para el presente análisis, 17 pacientes (43.6\%), contaron con el diagnóstico de diabetes mellitus tipo 2 previo al procedimiento quirúrgico y 21 pacientes (56.4\%), carecieron de este diagnóstico previo al procedimiento quirúrgico. En los pacientes no diabéticos, se encontraron diferencias estadísticamente significativas en los valores de índice de masa corporal en la comparación de medias entre el estado basal y a los 12 meses después de haber realizado el bypass gástrico, sin embargo, la hemoglobina glucosilada y la creatinina no mostraron diferencia significativa. En contraste, el grupo de pacientes diabéticos presentó diferencias estadísticamente significativas en las cifras de índice de masa corporal, hemoglobina glucosilada y ácido úrico. Conclusiones: El bypass gástrico laparoscópico proporciona pérdida de peso y reducción del IMC satisfactoria, en específico, el porcentaje de exceso de IMC perdido, con la mejora simultánea de comorbilidades relacionadas con la obesidad.

PALABRAS CLAVE: Obesidad. Diabetes. Bypass gástrico. Efectos metabólicos.

\author{
Correspondence: \\ *Federico López-Rosales \\ Calle 7433 × 20 y 22, Fracc. Altabrisa \\ C.P. 97130 , Mérida, Yuc., México \\ E-mail: flr770611@yahoo.com.mx
}

Date of reception: 14-03-2018

Date of acceptance: 24-04-2018

DOI: $10.24875 / C I R U E . M 18000049$
Cir Cir. 2018;86:298-305

Contents available at PubMed www.cirugiaycirujanos.com 


\section{Introduction}

Obesity is a systemic, progressive, chronic, multifactorial disease that has reached epidemic proportions in the world and constitutes a serious health problem because it generates an increase in associated morbidity and health costs, as well as a decrease in survival and quality of life ${ }^{1,2}$.

The American Association of Clinical Endocrinologists has defined obesity as an "adiposity-based chronic disease", a term that identifies a chronic disease, alludes to a pathophysiological basis and avoids the stigma related to the multiple meanings of obesity $^{3}$.

Obesity is a risk factor for numerous chronic-degenerative diseases, among which the most important are diabetes mellitus, cardiovascular diseases and different types of cancer. According to the 2016 National Health and Nutrition Survey, obesity affects $38.6 \%$ of females and $27.7 \%$ of males. In addition, there was an increase observed in the prevalence of diabetes with regard to 2012, which went from 9.2 to $9.4 \%$. Throughout the country, there is a higher prevalence in females than in males (10.3 vs. $8.4 \%)^{4}$.

Around $90 \%$ of type 2 diabetes mellitus cases have been estimated to be attributable to overweight and obesity $^{5}$. In adult patients, overweight and obesity are responsible for nearly $80 \%$ of type 2 diabetes mellitus cases, $35 \%$ of ischemic cardiovascular disease cases and $55 \%$ of hypertensive disease cases ${ }^{6}$.

Owing to its function in metabolic regulation, the gastrointestinal tract constitutes an important clinical and biological target for the management of diabetes ${ }^{7}$. In recent years, bariatric surgery indications have evolved from weight loss to metabolic contro| ${ }^{8,9}$. Although glycemic control is the primary goal, the ultimate goal is to reduce both microvascular (diabetic nephropathy, neuropathy and retinopathy) and macrovascular long-term complications (stroke, coronary artery disease and peripheral vascular disease).

"Metabolic surgery" is defined as the use of gastrointestinal surgery to treat diabetes mellitus and obesity. Currently, it is recommended for patients with grade III obesity (body mass index [BMI] $\geq 40 \mathrm{~kg} / \mathrm{m}^{2}$ ) regardless of the degree of glycemic control, as well as for patients with grade II obesity (BMI $35-39.9 \mathrm{~kg} / \mathrm{m}^{2}$ ) with inadequate glycemic control despite appropriated medical treatment and lifestyle changes.

Christou et al. ${ }^{10}$ reported a mortality rate of $6.2 \%$ in a study where a 5-year follow-up of patients was carried out after the performance of bariatric surgery, and concluded that the surgical procedure decreases long-term morbidity and mortality of obese patients, mainly cardiovascular risk and circulatory disease by $72 \%$. In contrast with the above, Adams et al..$^{11}$ reported a mortality rate of $4.1 \%$, and also documented that long-term mortality decreases by $40 \%$ in laparoscopic gastric bypass post-operated patients in comparison with the control group.

The first reports of statistically significant improvements after bariatric surgery in glycemic control figures in the treatment of patients diagnosed with type 2 diabetes mellitus and morbid obesity were presented in 1987 by Pories et al. ${ }^{12}$ and, ever since, numerous studies have demonstrated metabolic changes after bariatric surgery.

In 2004, Sjöström et al. ${ }^{13}$ demonstrated that the incidence of hypertriglyceridemia, diabetes and hyperuricemia were markedly lower in the group managed with bariatric surgery than in the control group after 2 and 10 years. In 2008, Lee et al..$^{14}$ demonstrated that $89.5 \%$ of diabetic patients with $\mathrm{BMI}<35$ had returned to euglycemia one year after the bypass, with a glycated hemoglobin reduction from 7.3 to $5.6 \%$.

One of the studies published so far that is representative of the above-mentioned, is the meta-analysis carried out by Buchwald et al. ${ }^{15}$, who documented better glycemic control and even diabetes remission after bariatric surgery during 1 to 2 years of follow-up.

Recently, two randomized studies have continued showing that bariatric surgery leads to better glycemic control rates than pharmacological therapy alone. Mingrone et al. $^{16}$ conducted a randomized study with 60 patients aged between 30 and 60 years with a $\mathrm{BMI}>35$ and an a history of more than 5 years with diabetes, who were randomly assigned to receive medical treatment or to undergo gastric bypass or biliopancreatic diversion. At 2 years, they reported the remission of diabetes in $75 \%$ of patients with gastric bypass and in $95 \%$ of patients with biliopancreatic diversion. At 5 years, $37 \%$ of patients with gastric bypass and $63 \%$ of those with biliopancreatic diversion maintained the diabetes remission, in comparison with none of the patients with medical treatment.

Schauer et al. ${ }^{17}$ carried out a randomized controlled trial with 150 diabetic patients, where they compared intensive medical management with gastric bypass or gastric sleeve. At 3 years, the primary endpoint (glycated hemoglobin $<6 \%$ ) was reached by $5 \%$ of the patients who received medical treatment in comparison with $38 \%$ of those who underwent gastric bypass 
and $24 \%$ of those who underwent gastric sleeve. At 5 years, the primary endpoint was reached by $5 \%$ of those who received medical management, in comparison with $29 \%$ in the gastric bypass group and $23 \%$ in the gastric sleeve group.

The above suggests that, as time after surgery increases, its benefits decrease. However, in a 7-year follow-up, the prevalence of dyslipidemia is reported to be lower in patients who underwent gastric bypass and adjustable gastric band procedures; the prevalence of diabetes and hypertension is lower only in the gastric bypass group ${ }^{18}$.

On the other hand, obesity has been implicated as a cause of urate overproduction and poor renal clearance ${ }^{19}$. Identified factors that can precipitate an acute episode of gout include infection, trauma, surgery, dietary transgression, total parenteral nutrition and uric acid-reducing therapy initiation ${ }^{20}$.

The High-Specialty Regional Hospital of the Yucatan Peninsula was the first institutional hospital of southeast Mexico to launch an obesity surgery multidisciplinary program, in the year 2010.

The purpose of this study is to describe and compare the changes in glucose, glycated hemoglobin, total cholesterol, triglycerides, high-density lipoprotein (HDL) cholesterol, low-density lipoprotein (LDL) cholesterol, creatinine, uric acid, weight and BMI figures in patients undergoing laparoscopic gastric bypass surgery prior to the procedure and 12 months after surgery at the High-Specialty Regional Hospital of the Yucatan Peninsula.

\section{Methods}

The study population included all patients who met the criteria for obesity surgery and who had undergone Roux-en-Y gastric bypass laparoscopic surgery at the High-Specialty Regional Hospital of the Yucatan Peninsula in the period between 2010 and 2015. A systematic review of 90 medical records was carried out, out of which only 39 met the selection criteria to participate in the study.

Descriptive statistics of quantitative variables (age, serum glucose, glycated hemoglobin, total cholesterol, triglycerides, HDL-cholesterol, LDL-cholesterol, creatinine, urea, weight and BMI) were carried out depending on their type of distribution. To determine the type of distribution, the Shapiro-Wilk normality test was used, adjusted to the study population sample size.

For qualitative variables (gender, type 2 diabetes mellitus diagnosis prior to surgery, hypertension diagnosis prior to surgery and obstructive sleep apnea syndrome diagnosis prior to surgery), simple frequencies and percentages were used.

Owing to the type of Gaussian distribution presented by the quantitative variables, parametric statistics were used. When normality was assumed, Student's t-test was used for related samples; the chi-square test was used for qualitative variables; when in any of the cells on the $2 \times 2$ table any of the expected values was $<5$, Fischer's exact test was used. A p-value $<0.05$ was considered to be statistically significant and the SPSS statistical package, version 21.0, was used.

\section{Results}

Of a total of 90 patients who underwent Y-en-Roux gastric bypass laparoscopic surgery, the sample was reduced to 38 patients because $52(57 \%)$ were excluded from the analysis given that they were lost to follow-up at the High-Specialty Regional Hospital of the Yucatan Peninsula.

As shown in table 1 , of the 38 patients included in the present analysis, 17 (43.6\%) had been diagnosed with type 2 diabetes mellitus prior to the surgical procedure. In both groups, with and without a diabetes diagnosis, there was a higher prevalence of females, with $88 \%$ (15 patients) having a diabetes diagnosis and $76 \%$ (16 patients) not having such diagnosis. Mean age was 41 years in the group of diabetic patients, in comparison with 35 years in the group of non-diabetics. The mean recorded for weight in the group of diabetic patients was $118.4 \mathrm{~kg}$, with a standard deviation of $16.7 \mathrm{~kg}$, while in the group of non-diabetic patients the recorded weight mean was $124 \mathrm{~kg}$ with, a standard deviation of $22.5 \mathrm{~kg}$. On the other hand, with regard to height in both groups, mean height in diabetic patients was $1.59 \mathrm{~m}$, with a standard deviation of $7.8 \mathrm{~cm}$, while in non-diabetics patients it was $1.60 \mathrm{~m}$, with a standard deviation of $9.6 \mathrm{~cm}$.

Derived from weight and height, mean BMI in the group of diabetic patients was $46 \mathrm{~kg} / \mathrm{m}^{2}$, with a standard deviation of $6.5 \mathrm{~kg}$, while in the group of non-diabetic patients BMI had a mean of $47.3 \mathrm{~kg} / \mathrm{m}^{2}$ with a standard deviation of $8.4 \mathrm{~kg}$.

As regards metabolic products, as it was to be expected, all recorded values were lower in non-diabetic patients, starting by serum glucose, with a mean of $93.4 \mathrm{mg} / \mathrm{dL}$ and a standard deviation of $8.4 \mathrm{mg}$ and, in accordance with that value, glycated hemoglobin had a mean of 4.9 with a standard deviation of 0.5 . 
Table 1. Baseline sociodemographic, anthropometric and metabolic characteristics

\begin{tabular}{|c|c|c|}
\hline Variable & \begin{tabular}{l}
\multicolumn{1}{c}{ Diabetic } \\
patients group \\
$n=17(43.6 \%)$
\end{tabular} & $\begin{array}{c}\text { Non-diabetic } \\
\text { patients group } \\
n=21(56.4 \%)\end{array}$ \\
\hline \multicolumn{3}{|l|}{ Gender* } \\
\hline Females & $15(88.2)$ & $16(76.2)$ \\
\hline Males & $2(11.8)$ & $5(23.8)$ \\
\hline Age $^{\dagger}$ (years) & $41.1(9.9)$ & $35.1(7.7)$ \\
\hline Weight $^{\dagger}(\mathrm{kg})$ & $118.4(16.7)$ & $124(22.5)$ \\
\hline Height $^{\dagger}(\mathrm{cm})$ & $159.8(7.8)$ & $160.5(9.6)$ \\
\hline $\mathrm{BMI}^{\dagger}\left(\mathrm{kg} / \mathrm{m}^{2}\right)$ & $46(6.5)$ & $47.3(4.9)$ \\
\hline Glucose $^{\dagger}(\mathrm{mg} / \mathrm{mL})$ & 107 (12.3) & $93.4(8.4)$ \\
\hline Glycated hemoglobin ${ }^{\dagger}(\%)$ & $6(0.6)$ & $4.9(0.5)$ \\
\hline 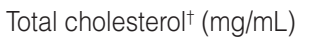 & $198(42)$ & $193(34.7)$ \\
\hline Triglycerides $^{\dagger}(\mathrm{mg} / \mathrm{mL})$ & $168.3(71.4)$ & $166(77.4)$ \\
\hline $\mathrm{HDL}$-cholesterol ${ }^{\dagger}(\mathrm{mg} / \mathrm{mL})$ & $44.5(9.8)$ & $41.7(8.9)$ \\
\hline 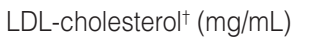 & $128.9(31)$ & $127.1(27.1)$ \\
\hline Creatinine $^{\dagger}(\mathrm{mg} / \mathrm{mL})$ & $0.7(0.1)$ & $0.6(0.2)$ \\
\hline Uric acid ${ }^{\dagger}(\mathrm{mg} / \mathrm{mL})$ & $5.3(1.0)$ & $5.2(1.2)$ \\
\hline \multicolumn{3}{|l|}{ Hypertension* } \\
\hline Yes & $7(41.2)$ & $16(76.2)$ \\
\hline No & $10(58.8)$ & $5(23.8)$ \\
\hline \multicolumn{3}{|l|}{ OSAS* } \\
\hline Yes & $2(11.8)$ & $16(76.2)$ \\
\hline No & $15(88.2)$ & $5(23.8)$ \\
\hline
\end{tabular}

*Data expressed as: frequencies (percentages).

tData presented as: mean (standard deviation).

BMl: body mass index; HDL: high-density lipoprotein; LDL: low-density lipoprotein; OSAS: obstructive sleep apnea syndrome.

Regarding the lipid profile, cholesterol had the highest mean differences between both groups, with a mean of $198 \mathrm{mg} / \mathrm{dL}$ and a standard deviation of $42 \mathrm{mg}$ in the diabetic patients' group, while in the group of non-diabetic patients, it had a mean of $193 \mathrm{mg} / \mathrm{dL}$ and a standard deviation of $34.7 \mathrm{mg}$. The lipid product that showed the lowest mean differences between both groups was HDL-cholesterol, which in the group of diabetic patients had a mean of $44.5 \mathrm{mg} / \mathrm{dL}$ and a standard deviation of $9.8 \mathrm{mg}$, while in the group of non-diabetic patients it had a mean of $41.7 \mathrm{mg} / \mathrm{dL}$ and a standard deviation of $8.9 \mathrm{mg}$.

In the renal function metabolic products, both for creatinine and for uric acid, the mean difference in both groups was 0.1 .

Finally, the group with the highest prevalence of systemic arterial hypertension and obstructive sleep apnea syndrome was observed to be the non-diabetic patients' group.

Once the gastric bypass was performed in the study population, anthropometric values and patient metabolic status were recorded again in both groups. The t-test was used for related samples. The Levene test was non-significant in all variables, and homogeneity of variances was thus assumed, as shown below.

Table 2 shows that statistically significant differences were found in all anthropometric values, but glycated hemoglobin and creatinine showed no significant difference in the comparison of means between baseline status and 12 months after having performed the gastric bypass. These findings allow to corroborate baseline metabolic control, as well as the renal function of patients in this group.

In contrast, in the group of diabetic patients, the only metabolic product that showed no statistical significance in the comparison of means between baseline status and 12 months after having undergone gastric bypass was serum creatinine. This is highly important, since with the resulting statistical significance, an important metabolic change is described in the patients under study, the primary impact of which would compromise the renal function, with a possible metabolic decompensation associated with the underlying disease diagnosed in the patients; however, the renal function remained without significant changes. As shown in table 3 , there is even a difference of a 0.1 decrease in mean serum creatinine at 12 months of follow-up.

When the rest of the metabolic products and anthropometric characteristics were analyzed in diabetic patients, we observed that both BMI and glycated hemoglobin, as well as uric acid, in addition to having a mean difference with statistical significance between the baseline status and at 12 months of follow-up, show confidence intervals that are accurate enough to emphasize the importance of bariatric surgery as an effective therapeutic measure for the decrease of these metabolic products 12 months after the gastric bypass was performed, and to demonstrate that this decrease was not attributed to chance.

The statistical significance found in both groups is of great clinical relevance, since the effectiveness of bariatric surgery as a therapeutic measure is verified not only for weight reduction, but also for metabolic control of both diabetic and non-diabetic patients, with renal function stability being safeguarded and without metabolic decompensation, as it might be expected in 
Table 2. Comparison of metabolic products and anthropometry at baseline and 12 months after surgery in the group of non-diabetic patients

\begin{tabular}{|c|c|c|c|c|}
\hline Variable & Baseline & 12 months & $p$ & $\mathrm{Cl}$ \\
\hline Veight* (kg) & $124(22.5)$ & $80.2(16.3)$ & 0.000 & $33.58-46.41$ \\
\hline $3 M I^{*}\left(\mathrm{~kg} / \mathrm{m}^{2}\right)$ & $47.3(4.9)$ & $31.4(5.5)$ & 0.000 & 13.51-17.63 \\
\hline Glucose* (mg/dL) & $93.4(8.4)$ & $83.1(7.2)$ & 0.001 & $5.00-14.90$ \\
\hline $\begin{array}{l}\text { Glycated } \\
\text { hemoglobin* }(\%)\end{array}$ & $4.9(0.5)$ & $5.1(0.6)$ & 0.283 & $0.21-0.68$ \\
\hline $\begin{array}{l}\text { Total cholesterol* } \\
\text { (mg/dL) }\end{array}$ & $193(34.7)$ & $156.7(20.5)$ & 0.000 & $21.76-51.68$ \\
\hline $\begin{array}{l}\text { HDL-cholesterol* } \\
\text { (mg/dL) }\end{array}$ & $41.7(8.9)$ & $58.6(9)$ & 0.000 & $11.51-25.05$ \\
\hline Uric acid* (mg/dL) & $5.2(1.2)$ & $4(1.2)$ & 0.001 & $0.65-1.93$ \\
\hline $\begin{array}{l}\text { LDL-cholesterol* } \\
(\mathrm{mg} / \mathrm{dL})\end{array}$ & $127.1(27.1)$ & $88.6(19.6)$ & 0.000 & $21.76-51.68$ \\
\hline $\begin{array}{l}\text { Triglycerides* } \\
\text { (mg/dL) }\end{array}$ & $166(77.4)$ & 74 (19.9) & 0.000 & $54.29-125.46$ \\
\hline Creatinine $^{*}(\mathrm{mg} / \mathrm{dL})$ & $0.6(0.2)$ & $0.6(0.1)$ & 0.537 & $-0.11-0.06$ \\
\hline
\end{tabular}

*Data presented as: mean (standard deviation).

BMI: body mass index; Cl: confidence interval; HDL: high-density lipoprotein; LDL low-density lipoprotein

a population as sensitive as type 2 diabetes mellitus-diagnosed patients are. However, it should be noted that diabetic patients who were considered to participate in this study had an adequate baseline metabolic control, as described at the beginning of the results section and in table 1 .

It is important to highlight a fundamental difference between both study groups. Glycated hemoglobin in diabetic patients showed a statistically significant decrease with a narrow confidence interval, which provides support to the above-mentioned claim. Bariatric surgery is an effective therapeutic measure for the remission of diabetes, defined as the return to normal glucose values (glycated hemoglobin $<6.5 \%$ or fasting glucose $<100 \mathrm{mg} / \mathrm{dL}$ ) for more than one year of duration without pharmacological therapy ${ }^{21}$. In the obtained results, glucose, just as glycated hemoglobin, showed a statistically significant decrease, since mean glucose at 12 months of follow-up was $81.4 \mathrm{mg} / \mathrm{dL}$, which enriches the definition of diabetes remission even with the standard deviation shown (7 mg/dL).

As shown in table 4, when comparing both groups at 12 months of follow-up, three variables of interest were contemplated: excess BMI loss percentage, complications experienced by patients due to the surgical procedure, and management of such complications.
Table 3. Comparison of metabolic products and anthropometry at baseline and 12 months after surgery in the group of diabetic patients

\begin{tabular}{|c|c|c|c|c|}
\hline Variable & Baseline & 12 months & $p$ & $\mathrm{Cl}$ \\
\hline Weight* $(k g)$ & $118.4(16.7)$ & $79.6(12)$ & 0.000 & $34.04-45.96$ \\
\hline $\mathrm{BMI}{ }^{*}\left(\mathrm{~kg} / \mathrm{m}^{2}\right)$ & $46(6.5)$ & $30.3(4.3)$ & 0.000 & $13.24-18.50$ \\
\hline Glucose $^{*}(\mathrm{mg} / \mathrm{dL})$ & 107 (12.3) & $81.4(7)$ & 0.000 & $19.18-31.87$ \\
\hline $\begin{array}{l}\text { Glycated } \\
\text { hemoglobin* }(\%)\end{array}$ & $6(0.6)$ & $5(0.6)$ & 0.000 & $0.57-1.46$ \\
\hline $\begin{array}{l}\text { Total cholesterol* } \\
\text { (mg/dL) }\end{array}$ & $198(42)$ & $171.7(31.2)$ & 0.016 & $5.55-47.03$ \\
\hline $\begin{array}{l}\text { HDL-cholesterol } \\
(\mathrm{mg} / \mathrm{dL})\end{array}$ & $44.5(9.8)$ & $60.3(15.2)$ & 0.001 & $8.41-24.25$ \\
\hline Uric acid* (mg/dL) & $5.3(1.0)$ & $3.9(0.9)$ & 0.000 & $0.80-2.10$ \\
\hline LDL-cholestero|* & $128.9(31)$ & $95.9(25)$ & 0.003 & $12.77-49.36$ \\
\hline
\end{tabular}
$(\mathrm{mg} / \mathrm{dL})$

$\begin{array}{lllll}\text { Triglycerides* }^{*} & 168.3(71.4) & 86.9(35.5) & 0.000 & 50.04-112.66\end{array}$ $(\mathrm{mg} / \mathrm{dL})$

Creatinine $^{*}(\mathrm{mg} / \mathrm{dL}) \quad 0.7(0.1) \quad 0.6(0.1) \quad 0.102 \quad-0.01-0.14$

*Data expressed as: mean (standard deviation).

BMl: body mass index; Cl: confidence interval; HDL: high-density lipoprotein; LDL: low-density lipoprotein.

The percentage of excess BMI loss has been recognized as the method to compare different obesity treatments. Since its publication in the year 2007 by Deitel et al. ${ }^{22}$, it has been adopted as the standard summary measure for studies whose final objective is the comparison of weight loss after carrying out a therapeutic intervention in a given population.

Currently, there are two objective summary measures to define weight loss in patients after a therapeutic intervention, either pharmacological or surgical: the percentage of excess weight loss and the percentage of excess BMI loss. In this work, the percentage of excess BMI loss was used as a summary measure, since it has greater objectivity and accuracy for establishing weight loss with clinical significance, which was important for the particular purposes of the present study. Weight expressed in kilograms has been proposed and used in several clinical studies with the purpose to mainly compare the therapeutic effect of drugs. However, when an 8-kg loss is reported in a patient diagnosed with morbid obesity, this goal is generally not significant in the comparison of weight before and after bariatric surgery. In addition, expressing the weight in kilograms alone is not related to height, which considerably varies in different regions of the same country, as the specific case of Mexico is. For example, the healthy weight for a subject with 
Table 4. Comparison of the percentage of excess BMI loss, postoperative complications and management between the group of diabetic patients and the group of non-diabetic patients

\begin{tabular}{lcccc}
\hline & $\begin{array}{c}\text { Group of } \\
\text { diabetic } \\
\text { patients }\end{array}$ & $\begin{array}{c}\text { Group of } \\
\text { non-diabetic } \\
\text { patients }\end{array}$ & $\mathbf{p}$ & $\mathbf{C l}$ \\
\hline \% EBMIL & $76.7(14.5)$ & $72.9(23.7)$ & 0.580 & $10.12,17.6$ \\
Complications $^{\dagger}$ & $4(23.5)$ & $2(9.6)$ & 0.378 & \\
Leak & $3(17.6)$ & $0(0)$ & & \\
Stenosis & $1(5.9)$ & $1(4.8)$ & & \\
$\begin{array}{l}\text { Petersen } \\
\text { hernia }\end{array}$ & $0(0)$ & $1(4.8)$ & \\
$\begin{array}{l}\text { Management } \\
{ }^{\dagger}\end{array}$ & $4(23.5)$ & $2(9.6)$ & 0.378 & \\
$\begin{array}{l}\text { Fasting and } \\
\text { TPN }\end{array}$ & $3(17.6)$ & $0(0)$ & \\
$\begin{array}{l}\text { Endoscopic } \\
\text { dilation }\end{array}$ & $1(5.9)$ & $1(4.8)$ & \\
$\begin{array}{l}\text { Surgical } \\
\text { closure }\end{array}$ & $0(0)$ & $1(4.8)$ & \\
\hline
\end{tabular}

*Data presented as: mean (standard deviation)

tData expressed as: frequency (percentage).

BMl: body mass index; \% EBMIL: percentage of excess BMI loss;

NPT: total parenteral nutrition.

tall stature will be of higher clinical relevance in comparison with the same weight in a subject of short stature. For this reason, we consider the comparison of excess BMI loss more useful owing to the construct it represents.

\section{Discussion}

This observational-descriptive study included 38 patients from the High-Specialty Regional Hospital of the Yucatan Peninsula diagnosed with morbid obesity who underwent laparoscopic gastric bypass, and compared the anthropometric and metabolic characteristics between the baseline status and 12 months after surgery. Of the 39 patients included, $43.6 \%$ had been diagnosed with type 2 diabetes mellitus prior to surgery, while $56.4 \%$ had no such diagnosis; this entailed a 1.24:1 ratio, but for clinical purposes we can specify a 5:4 ratio.

The presented results are consistent with the medical literature regarding the elevated serum concentrations of cardiovascular risk factors in obese patients (glucose, cholesterol, triglycerides, LDL-cholesterol and uric acid), and with the fact that these risk factors decrease in parallel to weight and BMI reduction once the surgical procedure is performed. In the present analysis, a decrease in serum triglycerides, total cholesterol and LDL-cholesterol concentrations was observed after surgery, whereas HDL-cholesterol, which has a cardioprotective function, was significantly increased. The renal function remained stable, even with a non-significant serum creatinine decrease (of 0.1 between baseline and at 12 months of follow-up) in the group of diabetic patients. Bariatric surgery is associated with a significant metabolic control of glucose and glycated hemoglobin in patients diagnosed with type 2 diabetes mellitus and other conditions associated with obesity, such as hypertension and hyperlipidemia. This has much more clinical significance, by conceptualizing bariatric surgery as a surgical procedure that improves metabolic conditions even in non-diabetic patients.

In a systematic review and meta-analysis of 136 studies conducted by Buchwald et al. ${ }^{15}, 19.4 \%(n=3,769)$ of patients were reported to be males and $72.6 \%(n=$ $14,082)$ females. Mean age was 39 years and baseline mean BMl for all 16,944 patients was $46.8 \mathrm{~kg} / \mathrm{m}^{2}$. This is consistent with findings in the present study, where a female prevalence higher than $75 \%$ was observed in both groups, but with regard to age, the means are slightly discordant with those published Buchwald et al. ${ }^{15}$, since in the group of diabetic patients, the mean was 41.1 years and in non-diabetics it was 35.1 years; however, this does not represent a statistically significant difference. The BMI reported at baseline status is consistent with that which was published by said authors.

In a study carried out by Robert et al. ${ }^{23}$, the impact of bariatric surgery on metabolic factors involved in the remission of type 2 diabetes mellitus was analyzed. A follow-up of patients was carried out for one year, and $62.8 \%$ were reported to have diabetes remission. A baseline BMI $\leq 50 \mathrm{kgm}^{2}$, glycated hemoglobin $\leq 7.1 \%$ and absence of insulin therapy were considered to be preoperative predictors of diabetes remission. Short diabetes duration and a good preoperative glycemic control increase the rate of type 2 diabetes mellitus remission one year after surgery.

In 2008, Friedman et al. ${ }^{24}$ conducted a prospective study with 411 patients undergoing laparoscopic gastric bypass, out of which 21 had been previously diagnosed with gout. Seven of the 21 patients had a postoperative acute gout attack. One possible explanation is that, in the postoperative period, patients are indicated a minimum daily intake of $60 \mathrm{~g}$ of protein. In 2014, Dalberth et al. ${ }^{25}$ reported a prospective study where 60 diabetic patients underwent gastric sleeve laparoscopic surgery and were followed for one year. Two weeks after surgery, uric acid values did significantly increase, but decreased at 3 months and remained low for the rest of the follow-up period. 
The above is not assessable with the observations reported in this study, since only the variables under study were measured at one year of follow-up, and the uric acid behavior 2 weeks after the surgical procedure is unknown. However, a statistically significant uric acid decrease was reported in both study groups, as well as a stable renal function during that period, with a difference of a 0.1 decrease in mean serum creatinine in the group of diabetic patients at 12 months of follow-up.

Finally, one factor that is widely considered in the medical literature on bariatric surgery, weight and BMI loss, as well as diabetes mellitus type 2 remission and the metabolic products involved, is the recovery of weight and BMI loss in the postoperative period. According to reports in the literature, weight recovery begins at between 18 and 24 months of surgery, and 30 to $64 \%$ of patients experience weight recovery when 2 years have elapsed since the surgery ${ }^{26,27}$.

Patients who undergo bariatric surgery are required to comply with rigorous dietary changes in order to ensure sustained weight loss and to prevent complications such as vomiting and dumping syndrome ${ }^{28}$.

Compliance with surgical follow-up visits has been associated with improved eating habits ${ }^{29}$ and higher degrees of physical activity ${ }^{30}$, whereas inadequate follow-up visits attendance has been associated with a lower percentage of excess weight and BMI loss ${ }^{31,32}$. Healthy behaviors and eating patterns, including exercise and psychological counseling for the reinforcement of healthy behaviors, evidently can help patients maintain weight in the long term ${ }^{33}$.

Our findings should be interpreted within of the context of certain limitations. In the first place, the study is descriptive and purely observational, which hinders establishing causal conclusions about the reported findings. It would be convenient for studies with larger numbers of patients and closer monitoring during the first postoperative year to be carried out, and following-up on patients for at least 24 months, which is a crucial period for the recovery of weight and BMI loss. In patients diagnosed with diabetes mellitus type 2, bariatric surgery cannot be established as a cause for the observed improvement, since the time since diagnosis and the pharmacological therapy used should be contemplated. In case of having studies available that include the above-mentioned characteristics, data can be assessed using multivariate models in order to control for metabolism final variables based on baseline status confounders, and thereby establishing causal conclusions.

\section{Conclusions}

Obesity constitutes a health, economic, social and psychological problem that generates premature mortality, increased use of health services, decreased quality of life, disability and chronic morbidity; it is considered a fundamental pillar in the incidence of diabetes mellitus worldwide. Gastric bypass provides satisfactory weight loss and BMI reduction, specifically in the percentage of excess BMI loss, with a simultaneous improvement in obesity-related comorbidity. The findings of the present study are consistent with those published in the medical literature; laparoscopic gastric bypass therapeutic effect is more significantly observed in patients with $\mathrm{BMI}<50$, which implies that preoperative BMI is a strong determinant in patient metabolic control final outcome.

The fundamental challenge in the postoperative period of obese patients, whether or not they are diagnosed with type 2 diabetes mellitus, is weight loss maintenance and, therefore, the maintenance metabolic product values, both glucose and lipid profile. This lies in close patient follow-up by a multidisciplinary team, aimed at patient education in terms of eating behaviors and patterns, as well as at building the habit of physical activity in patients.

\section{References}

1. Organización Mundial de la Salud (OMS), Obesidad y sobrepeso. Disponible en: http://www.who.int/es/news-room/fact-sheets/detail/obesity-and-overweight. Consultado Octubre 2017.

2. Hussain SS, Bloom SR. The pharmacological treatment and management of obesity. Postgrad Med. 2011;123:34-44.

3. Mechanick JI, Hurley DL, Garvey WT. Adiposity-based chronic disease as a new diagnostic term: American Association of Clinical Endocrinologists and the American College of Endocrinology position statement. Endocr Pract. 2017;23:372-8.

4. Instituto Nacional de Salud Pública. Encuesta Nacional de Salud y Nutrición de Medio Camino, 2016. Informe final de resultados. Disponible en: http://promocion.salud.gob.mx/dgps/descargas1/doctos_2016/ensanut_mc_2016-310oct.pdf.

5. Dávila-Torres J, González-Izquierdo JJ, Barrera-Cruz A. Panorama de la obesidad en México. Rev Med Inst Mex Seguro Soc. 2015; 53:240-9.

6. Banegas JR, López-García E, Gutiérrez-Fisac JL, Guallar-Castillón P, Rodríguez-Artalejo F. A simple estimate of mortality attributable to excess weight in the European Union. Eur J Clin Nutr. 2003;57:201-8.

7. Rubino F, Nathan DM, Eckel RH, Schauer PR, Alberti KG, Zimmet PF, et al. Metabolic surgery in the treatment algorithm for type 2 diabetes: a joint statement by International Diabetes Organizations. Surg Obes Relat Dis. 2016;12:1144-62.

8. Rubino F, Gagner M, Gentileschi P, Kini S, Fukuyama S, Fenj J, et al. The early effect of the Roux-en-Y gastric bypass on hormones involved in body weight regulation and glucose metabolism. Ann Surg. 2004;240:236-42.

9. Schauer PR, Burguera B, Ikramuddin S, Cottam D, Gourash W, Hamad G, et al. Effect of laparoscopic Roux-en-Y gastric bypass on type 2 diabetes mellitus. Ann Surg. 2003;238:467-84, discussion 484-5.

10. Christou NV, Sampalis JS, Liberman M, Look D, Auger S, McLean AP, et al. Surgery decreases long-term mortality, morbidity and health care use in morbidly obese patients. Ann Surg. 2004;240:416-23.

11. Adams TD, Gress RR, Smith SC, Halverson RC, Simper SC, Rosamond WD, et al. Long-term mortality after gastric bypass surgery. $\mathrm{N}$ Engl J Med. 2007;357:753-61.

12. Pories WJ, Caro JF, Flickinger EG, Meelheim HD, Swanson MS. The control of diabetes mellitus (NIDDM) in the morbidly obese with the Greenville Gastric Bypass. Ann Surg. 1987;206:316-23. 


\section{J.D. Hernández-Marín, et al.: Metabolic changes in obese patients after laparoscopic gastric bypass}

13. Sjöström L, Lindroos AK, Peltonen M, Torgerson J, Bouchard C Carlsson B, et al. Lifestyle, diabetes, and cardiovascular risk factors 10 years after bariatric surgery. N Engl J Med 2004;351:2683-93.

14. Lee WJ, Wang W, Lee YC, Huang MT, Ser KH, Chen JC. Effect of laparoscopic mini-gastric bypass for type 2 diabetes mellitus: comparison of $\mathrm{BMI}>35$ and $<35 \mathrm{~kg} / \mathrm{m}^{2}$. J Gastrointest Surg. 2008;12:945-52.

15. Buchwald H, Estok R, Fahrbach K, Banel D, Jensen MD, Poires WJ et al. Weight and type 2 diabetes after bariatric surgery: systematic review and meta-analysis. Am J Med. 2009;122:248-56.

16. Mingrone G, Panunzi S, De Gaetano A, Guidone C, laconelli A, Nanni G et al. Bariatric-metabolic surgery versus conventional medical treatmen in obese patients with type 2 diabetes: 5 year follow-up of an open-label, single-centre, randomized controlled trial. Lancet. 2015;386:964-73.

17. Schauer PR, Bhatt DL, Kirwan JP, Wolski K, Aminian A, Brethauer SA, et al. Bariatric surgery versus intensive medical therapy for diabetes 5-year outcomes. N Engl J Med. 2017;376:641-51.

18. Courcoulas AP, King WC, Belle SH, Berk P, Flum DR, García L, et al. Seven-year trajectories and health outcomes in the Longitudinal Assessment of Bariatric Surgery (LABS) study. JAMA Surg. 2018;153:427-34.

19. Choi HK, Mount DB, Reginato AM. Pathogenesis of gout. Ann Intern Med. 2005;143:499-516.

20. McLean L. The pathogenesis of gout. En: Hochberg MC, editor. Reumathology. $3^{\text {rd }}$ ed. Edinburgh: Mosby; 2003. p. 211-256

21. Buse JB, Caprio S, Cefalu WT, et al. How do we define cure of diabetes? Diabetes Care 2009; 32: 2133-2135.

22. Deitel M, Gawdat K, Melissas J. Reporting weight loss 2007. Obes Surg. 2007; $17: 565-8$

23. Robert M, Ferrand-Gaillard C, Disse E, Espalieu P, Simon C, Laville M, et al. Predictive factors of type 2 diabetes remission 1 year after bariatric surgery: impact of surgical techniques. Obes Surg. 2013;23:770-5.
24. Friedman JE, Dallal RM, Lord JL. Gouty attacks occur frequently in postoperative gastric bypass patients. Surg Obes Relat Dis. 2008;4:11-5.

25. Dalberth N, Chen P, White M, Gamble GD, Barrat-Boyes C, Gow PJ, et al. Impact of bariatric surgery on serum urate targets in people with morbid obesity and diabetes: a prospective longitudinal study. Ann Rheum Dis. 2014;73:797-802.

26. Hsu LK, Benotti PN, Dwyer J, Roberts SB, Saltzman E, Shikora S, et al. Nonsurgical factors that influence the outcome of bariatric surgery: a review. Psychosom Med. 1998;60:338-46.

27. Magro DO, Geloneze B, Delfini R, Pareja BC, Callejas F, Pareja JC. Long-term weight regain after gastric bypass: a 5-year prospective study. Obes Surg. 2008;18:648-51.

28. Sarwer DB, Dilks RJ, West-Smith L. Dietary intake and eating behavior after bariatric surgery: threats to weight loss maintenance and strategies for success. Surg Obes Relat Dis. 2011;7:644-51.

29. Sarwer DB, Moore RH, Spitzer JC, Wadden TA, Raper SE, Williams NN. A pilot study investigating the efficacy of postoperative dietary counseling to improve outcomes after bariatric surgery. Surg Obes Relat Dis. 2012;8:561-8.

30. Vidal P, Ramón JM, Goday A, Parri A, Crous X, Trillo L, et al. Lack of adherence to follow-up visits after bariatric surgery: reasons and outcome. Obes Surg. 2014;24:179-83.

31. Freire RH, Borges MC, Álvarez-Leite JI, Toulson Davisson Correia MI. Food quality, physical activity, and nutritional follow-up as determinant of weight regain after Roux-en-Y gastric bypass. Nutrition. 2012;28:53-8.

32. Gould JC, Beverstein G, Reinhardt S, Garren MJ. Impact of routine and long-term follow-up on weight loss after laparoscopic gastric bypass. Surg Obes Relat Dis. 2007;3:627-30.

33. Westenhoefer J, Pudel V. Pleasure from food: importance for food choice and consequences of deliberate restriction. Appetite. 1993;20:246-9. 